American Journal of Agricultural and Biological Sciences 6 (3): 348-355, 2011

ISSN 1557-4989

(C) 2011 Science Publications

\title{
Optimization of Solenoid Valve for Variable Rate Application System
}

\author{
Saleh Mufleh Al-Saqer and Ghulam Mubashar Hassan \\ Department of Agriculture Engineering, College of Food and Agriculture Sciences, \\ King Saud University Riyadh, Saudi Arabia
}

\begin{abstract}
Problem statement: The aim of this research was to optimize the performance of solenoid valve used in Variable Rate Application System (VRA) in term of time response. The overall time response is usually divided into four parts i.e., plunger opening time, pressure opening time, plunger closing time and pressure closing time. Approach: The performance and design of the a solenoid valve used in VRA was analyzed methematically and experimentally. Voltage, current, pressure, spring constant, flow rate and mass of the plunger were found to be the main parameters affecting the performance of solenoid valve. Based on the analyses, some modifications were introduced in the design of the solenoid valve to enhance its performance. The newly designed solenoid valve was tested by varying the main parameters and its performance was compared in terms of time response. Results: The time respnose of the modified valve showed improvement. The plunger closing time for the modified valve improved by $79 \%$. Depending on the types of nozzle, the pressure opening and closing time responses were reduced by $37-53 \%$ and $55-73 \%$ respectively. It was also observed time response was improved by $34 \%$ when springs with lower spring constants are used. Conclusion: After thorough testing of both the original and proposed valves, it was observed that proposed valve average performance is faster than the original valve by $22 \mathrm{msec}$ or $56 \%$. However, it was also found that it is mandatory to increase the operating voltage of propsed valve for the better performance.
\end{abstract}

Key words: Solenoid valve, precision agriculture, spraying system, texas industrial remcor, variable rate application, solenoid valve optimization

\section{INTRODUCTION}

The field of Agriculture has experienced revolution with the advancement in electrical and mechanical engineering. Nowadays, Precision Agriculture systems or Variable Rate Application system (VRA) are widely adopted to improve both quality and quantity of crop yields, eliminate costs of farming process and decrease effects of applying fertilizer and pesticide to the crops (Bowers et al., 2001). For better yield, the crop inputs such as fertilizer, pesticides, etc. should be applied at variable application rates by electromechanical systems. This variability can be measured by optical sensors which provide continuous stream of data to the controller so that inputs can be varied over small areas throughout the field (Liaghat and Balasundram, 2010; Ezrin et al., 2010).

There are some challenges associated with use of these sensors such as accuracy of the collected data, time required for transferring the data to the spraying system, etc. The response time plays a critical role because any delay in the response may lead to misapplication of the treatment on targeted area. In this process, the time delay is combination of time delays associated with transferring the data to spraying system, spraying system and speed of vehicle and fluid (ElMarazky et al., 2011).

An important factor that must be considered for the use of VRA is its response time which is the time between the emission of the control signal to actuate the valve and the effective corresponding change of application rate. This response time depends on several essential system factors. With higher frequency of switching of valve, fine application resolution can be achieved. This switching is limited because of physical characteristics of the valve (Holtz et al., 2000).

Solenoid valves are widely used in many fields whenever fluid flow has to be controlled automatically. The wide variety of different designs enables the users to choose a valve optimal for their application. The solenoid valve switching i.e. opening and closing, is controlled by an electromagnetic force. For opening the valve, it is energized which builds the magnetic field and pulls the plunger against the action of a spring.

Corresponding Author: Saleh Mufleh Al-Saqer, Department of Agriculture Engineering, College of Food and Agriculture Sciences, King Saud University Riyadh, Saudi Arabia 
The dynamic behavior of solenoid valves has been comprehensively studied by many researchers. Lu and Jensen (2003) presented a model of the dynamic response for a fast-action micro-solenoid valve for pulsed detonation fuel injection. They found that the valve opening lagged by a constant time delay for a range of frequencies from $50-110 \mathrm{~Hz}$ when excited at 12 volts. The magnetizing current lags the exciting current creating a phase delay at all frequencies.

Pohl et al. (2002). developed a semi-empirical dynamic simulation model of a fast switching valve. The model predicted the valve's characteristics for a wide range of working conditions in the form of supply pressure and voltage. The characteristics of the valve that they studied were current flowing through the coil of the solenoid, magnetic flux density and the armature displacement.

Zheng (2001) presented theoretical and experimental study of the dynamic response of a cylinder deactivation hardware system. The dynamic response was characterized by a physical model. Through simulation and experimental data analysis, the effect of operating conditions on the dynamic response was studied and characterized over a wide range of operating conditions.

Holtz et al. (2000) evaluated the dynamic response of three commercially available sprayer valves used in variable rate applications of fertilizer and pesticides. Also, the study identified the minimum treatment distances for different ground speeds for each valve.

Shengchang et al. (2001) developed a mathematical model for a high speed digital valve and identified the design principles to optimize solenoid valve performance which are: (i) voltage and current should be high (24 volts) and low respectively, (ii) magnetic material with low conductivity is advantageous, (iii) magnetic path length should be shorter, (iv) Stroke should be smaller to reduce the flow force (v) connecting coils in parallel allows high-speed operation and (vi) armature mass needs to be smaller for higher acceleration.

The response time of solenoid valve comprises of plunger and pressure opening and closing time delays. The objectives of this research was to optimize the performance of the solenoid valve used in VRA in terms of the time response.

\section{MATERIALS AND METHODS}

The experimental setup included a pressure vessel valve to adjust the pressure, a pressure container connected to the air pressure supply, three solenoid valves, four pressure gauges and four fluid valves as shown in Fig. 1. The solenoid valve used in this research is Texas Industrial Remcor 2602. The valve was a direct lift type i.e., the coil pulled the plunger to a stop in the coil housing acting against the pressure of the liquid plus the spring compression force. The plunger moves $1.24 \mathrm{~mm}$ from closed to open state. The diameter of the orifice of the valve was $7.8 \mathrm{~mm}$. The maximum operating pressure of the valve was $551.6 \mathrm{kPa}$ (80 psi). The manufacture's specification for operation recommends that the voltage, current and maximum pressure should be 12 volts, 0.85 amperes and $862 \mathrm{kPa}$ (125 psi) respectively.

The source of the pressure in this experiment was the air pushed into the pressure container to force the liquid to flow at the desired pressure. Four Ashcroft pressure gauges made by Delavan-Delta Inc. were used to measure the pressure in the test apparatus. A 12 Volts function generator was used to generate the solenoid valve drive signals. A Harrison Laboratories Inc. manufactured variable voltage power supply, Model No. 809A, was used to supply power for the solenoid valve.

The voltage applied to the solenoid was measured with a Fluke 77 III multimeter manufactured by Fluke Corporation USA. In order to obtain the valve response to an input signal, pressure transducer was installed near to the nozzle in each tested valve by drilling into the valve body until reaching the fluid chamber. Two pressure transducers (MSP-400-250-P-4-N-1) were used in this research. The pressure range for this transducer is 0-250 psi, the output from 1-5 volts with 10-30 V supply and pressure port using $1 / 4$ ', NPT threads.

For accurate measurements, the pressure transducers were installed in the flow path near to the nozzle. Signals produced by the solenoid valve i.e., solenoid voltage, pressure and time were captured by a digital oscilloscope Tektronix Inc. USA (Model: TDS 210).

Two different types of nozzles were tested. Three orifices having different diameters were used for each type of nozzle. The first type i.e. Quick Tee Jet included Quick Tee Jet TP00015-SS, TP0003-SS and TP0006-SS and the flow rates of those nozzles are $0.568 \mathrm{~L} \mathrm{~min}^{-1}$ (0.15 GPM), 1.14 $\mathrm{L} \mathrm{min}^{-1}$ (0.3 GPM) and $2.27 \mathrm{~L} \mathrm{~min}^{-1}$ (0.6 GPM) respectively as reported by Spraying Systems Corp. The second type of nozzle was Stream Jet by NTech Inc. having three different sized nozzles. These nozzles were made from a Spraying Nozzle System Co. custom drilled for three orifices by NTech Industries, Inc. These nozzles were Stream Jet 0163, Proposed Stream Jet 0360 and Stream Jet 0667 having flow rates of $0.617 \mathrm{~L} \mathrm{~min}^{-1}(0.163 \mathrm{GPM}), 1.36 \mathrm{~L} \mathrm{~min}^{-1}$ (0.360 GPM) and $2.52 \mathrm{~L} \min ^{-1}$ (0.667 GPM), respectively. 
Am. J. Agri. \& Biol. Sci., 6 (3): 348-355, 2011

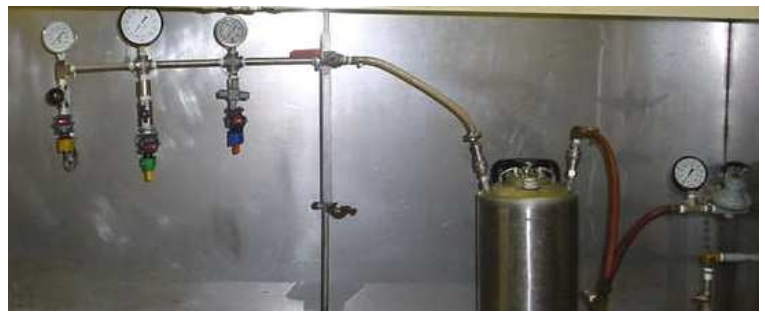

Fig. 1: Experimental test bed

Each test was repeated thrice resulting in three replicas for each nozzle. The same sets of nozzles were used with both original and proposed valves. The valve was set to perform at least three duty cycles before taking any measurements on the oscilloscope to ensure its performance. Water was chosen to be the liquid used in all the experiments.

The Pulse Width Modulation (PWM) technique uses digital signals as its input to the solenoid. The signal is instantaneous and the critical issue is the time it takes the solenoid valve to actuate i.e., the time between when the signal is applied and the valve action is completed. The PWM procedure requires a very fast response from the solenoid valve to be effective. Therefore, solenoid valve dynamics needs to be analyzed to improve its performance. Eq. 1 describes the mathematical model of the solenoid presented by Shengchang et al. (2001):

$m \ddot{y}+C_{d} \dot{y}+K y=\frac{2 \mu_{o} \pi N^{2} \dot{i}^{2}}{\frac{4 x}{d}+\frac{y}{d+y}}+A_{p} \frac{\rho \dot{y}^{2}}{2 C_{d}}$

where $\mathrm{m}$ is plunger's mass, $\mathrm{d}$ is plunger's diameter, $\mathrm{x}$ is plunger's displacement, $A_{p}$ is plunger's area of surface subject to pressure, $C_{d}$ is damping coefficient, $\mathrm{K}$ is spring constant, $\mathrm{y}$ is variable gap in the direction of magnetic flux path, $\mu_{\mathrm{o}}$ is permeability of free space, $\mathrm{N}$ is number of turns per unit length, $\mathrm{i}$ is current and $\rho$ is mass density of fluid. In this equation it can be observed that electromagnetic force needs to overcome the fluid and the mechanical forces. Therefore, in order to move the plunger faster against all these forces, the electromagnetic characteristics need to be altered. Hence, increasing the current in the solenoid coil will increase the magnetism and will linearly increase the solenoid force.

The solenoid valve was operated at three levels of voltages i.e. 12 volts, 24 volts and 36 volts. The temperature of the solenoid coil increases with the increase in voltage and reduces the current in the coil which lower the available push or pull. Thus, in order to avoid heating of the coil of solenoid, the duty cycle for the valves were set to less than half second. Also, after running any test, cooling time of at least five minutes was provided to keep the temperature low.

It has been noticed from Eq. 1, that the forces closing the plunger are spring force and fluid force. Thus, the spring pushes the plunger toward the orifice when the coil is discharged. Hence, it was assumed that by increasing the spring force, the valve would close faster and vice versa.

Different pressures in the range of $10 \mathrm{psi}$ to $80 \mathrm{psi}$ in 8 steps were tested. According to Eq. 1, the valve needs to overcome the spring force to open the plunger. So, speed of opening the valve is inversely proportional to the spring constant. On the other hand, spring constant is directly proportional to the speed of closing the valve. Thus, different springs having different spring constants were also tested to examine its effect.

The reduction of mass of plunger was expected to improve the plunger's performance in both the directions. Thus the modifications were proposed to reduce the mass of plunger. However, reducing the mass of the plunger would reduce the electromagnetic force, because the magnetic field will be not be sufficient to pull the "new" plunger to open.

The new or proposed plunger design was finalized after considering three modifications. In first modification, a hole was drilled axially through the plunger from the top to the bottom, but not through the plunger rubber seat and a piece of metal was used to cover the hole. Second modification was similar to the first one except that instead of covering the plunger's head, a piece of iron as large as the original head was inserted inside the plunger to replace the old one. Finally, the third modification was accomplished by incising grooves on the six sides of the plunger. The third modification was found to be better than earlier two because it avoided reducing the mass from the topside of the plunger, where the magnetic attraction primarily occurs. Also, by incising the sides of the plunger, the fluid was expected to flow out faster around the plunger during the closing operation and resulted in accelerating the closing process. The newly designed plunger was reduced from 12.24 gm to 6.53 $\mathrm{gm}$ and was slightly longer than the original one. This shortened the gap which plunger needs to cover from closed to open position. As electromagnetic force is inversely proportional to the distance between the objects, for the same speed, shortening the distance will reduce the traveling time. Figure 2 presents the dimensions of the original and the proposed plungers and Table 1 presents comparisons between the two designs. 

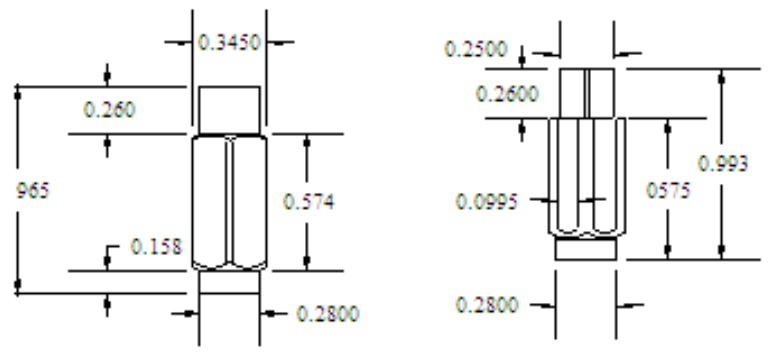

Fig. 2: Original (left) and proposed (right) plunger

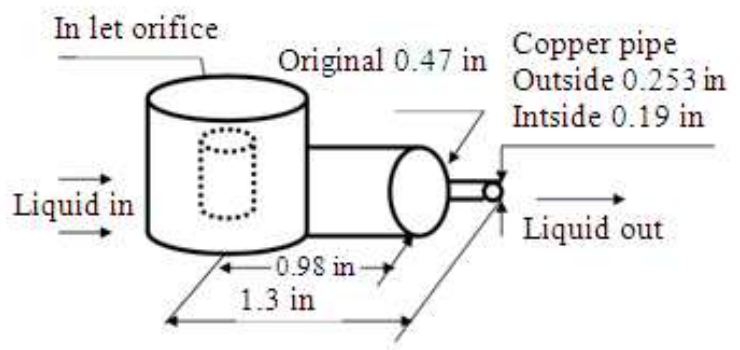

Fig. 3: Original valve seat with copper pipe installed

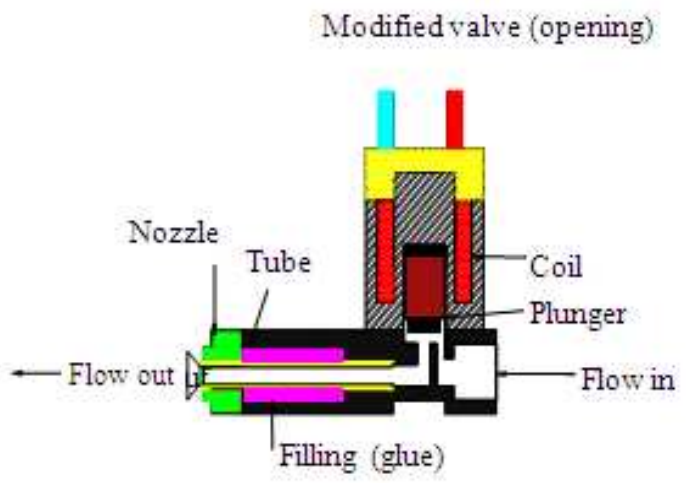

Fig. 4: The proposed valve in opening position

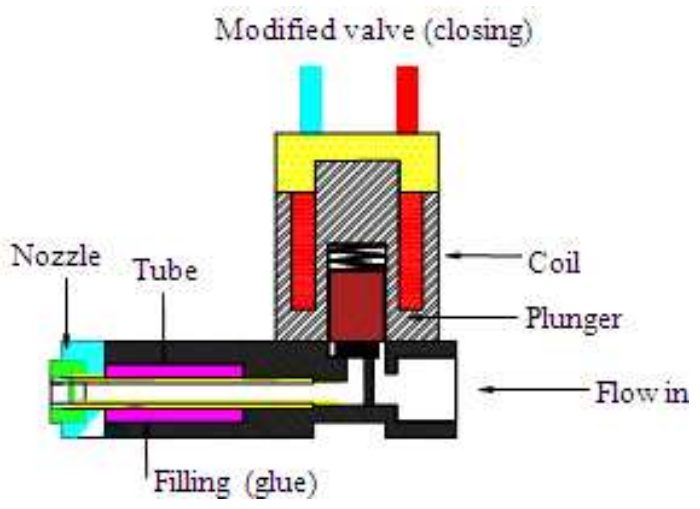

Fig. 5: The proposed valve in closing position

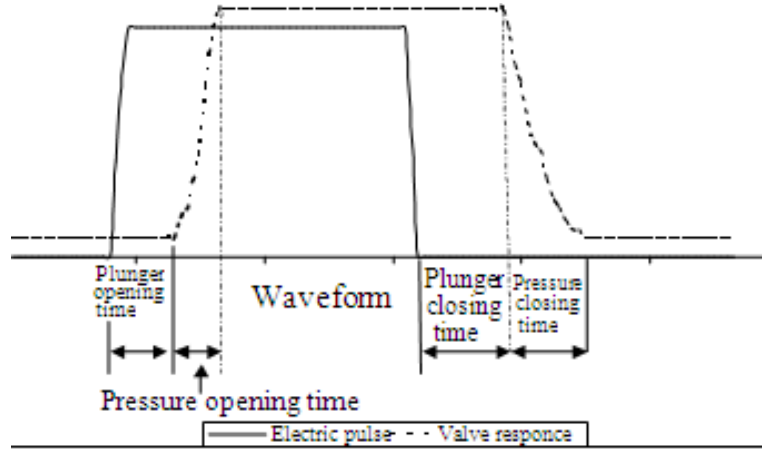

Fig. 6: Typical simulation waveforms for the input and valve's response

Table 1: Comparison between original and proposed plungers

\begin{tabular}{lll}
\hline Measurement & Original & Proposed \\
\hline Length (in.) & 0.965 & 0.993 \\
Weight (gm.) & 12.24 & 6.530 \\
\hline
\end{tabular}

The process of closing the valve starts when voltage applied to coil is turned off. After that, the flow decreases in a linear fashion as the plunger seals the orifice. This operation consumes considerable time which was expected to be reduced by increasing the speed of the plunger. Furthermore, during the initial tests of the solenoid valve, it was observed that the closing time for the same valve varied from one nozzle to another especiallly the delay increases when spraying with lower flow rate nozzles. The same result was observed when the original plunger was replaced with the proposed one. Thus, to improve plunger's performance, valve also needs modification in design.

During the process of valve closure, the plunger seals over the valve seat while the nozzle continues draining the remaining volume of liquid in the cavity between the valve seat and the nozzle. This problem was more evident at lower flow rates where drainage takes longer time because the nozzle's orifice was smaller.

To reduce the volume after the valve orifice without effecting the flow rate of the valve, several modifications were proposed which led eventually to the final design shown in Fig. 3. In this design, a copper pipe was installed into the valve. This pipe was inserted inside the outlet orifice carrying the flow to the nozzle directly. The volume of the valve was reduced by $78 \%$ i.e. from 0.17 in 3 to $0.037 \mathrm{in} 3$. The opening and closing of the valve is depicted in Fig. 4 and 5 respectively.

The time corresponding to the valve opening and closing was divided into following four phases as shown in Fig. 6: 
- Plunger opening time: The time between applying voltage to the coil and plunger's movement from the closed position

- Pressure opening time: The time between movement of plunger from closed position and pressure attaining its maximum value

- Plunger closing time: The time between turning off the voltage and plunger's movement back to the closed position

- Pressure closing time: the time between plunger's movement back to closed position and no flow coming out of nozzle

\section{RESULTS}

Several modifications were introduced to enhance the performance of the original solenoid valve used in VRA. These modifications resulted in the final proposed design. Experiments were conducted to analyze and compare the performance of both original and proposed solenoid valves. Furthermore, the effect of using different springs in the proposed solenoid valve was also analyzed. For precise measurements, the waveform was captured by the oscilloscope in the form of voltage and time. The sampling period was set to be $2 \mu \mathrm{sec}$, which enabled to track minor changes in the valve's performance.

Plunger opening time: The solenoid valve was operated at voltage range from $10-40$ volts. Table 2 summarizes the case of varying voltage on original valve using 00015 Quick TeeJet Nozzle. Table 3 presents the average of the plunger opening time at different level of pressures and voltages for original and proposed valves. The average value is taken because plunger opening time is independent of the nozzle type.

Pressure opening time: Before discussing the time, it was important to find effect of pressure on the minimum operating voltage of the valve. As mentioned earlier in Eq. 2 that increasing the pressure is directly proportional to electromagnetic force while keeping the other variables constant. In order to measure this effect, a test was conducted with both original and modified valves. The results are presented in Table 4 where the valves were operated between 10 and 80 psi with increments of $10 \mathrm{psi}$ in each step. At each level, voltage was increased from zero to minimum operating voltage where valve started operating.

The comparison of pressure opening time for different nozzles is presented in Table 5. As voltage does not play any pivotal role in the pressure opening time, thus the average results of all voltages was considered.
Table 2: Plunger's opening time variation w.r.t. voltage for original

\begin{tabular}{llllll}
$\begin{array}{l}\text { Voltage } \\
\text { (volts) }\end{array}$ & $\begin{array}{l}\text { Time } \\
(\mathrm{m} \mathrm{sec})\end{array}$ & $\begin{array}{l}\text { Voltage } \\
(\text { volts })\end{array}$ & $\begin{array}{l}\text { Time } \\
(\mathrm{m} \mathrm{sec})\end{array}$ & $\begin{array}{l}\text { Voltage } \\
(\text { volts })\end{array}$ & $\begin{array}{l}\text { Time } \\
(\mathrm{m} \mathrm{sec})\end{array}$ \\
\hline 10 & 27.6 & 20 & 7.0 & 32 & 5.00 \\
11 & 18.2 & 22 & 7.0 & 34 & 5.00 \\
12 & 18.6 & 24 & 5.3 & 36 & 3.60 \\
14 & 11.4 & 26 & 5.1 & 38 & 3.60 \\
16 & 10.8 & 28 & 5.1 & 40 & 2.28 \\
18 & 10.6 & 30 & 5.0 & & \\
\hline
\end{tabular}

Table 3: Plunger opening time average for original and proposed valves

\begin{tabular}{|c|c|c|c|c|c|c|}
\hline \multirow{3}{*}{$\begin{array}{l}\text { Voltage } \\
\text { (volts) }\end{array}$} & \multicolumn{6}{|c|}{$\begin{array}{l}\text { Average plunger opening } \\
\text { time }(\mathrm{m} \mathrm{sec}) \text { w. r. t. different pressures }\end{array}$} \\
\hline & \multicolumn{2}{|l|}{$30 \mathrm{psi}$} & \multicolumn{2}{|l|}{$40 \mathrm{psi}$} & \multicolumn{2}{|l|}{$50 \mathrm{psi}$} \\
\hline & Original & Proposed & Original & Proposed & Original & Proposed \\
\hline $12 *$ & 13.8 & 16.2 & 16.5 & 26.0 & 23.0 & 25.0 \\
\hline 24 & 6.0 & 6.0 & 5.6 & 7.1 & 6.5 & 7.3 \\
\hline 36 & 4.5 & 4.4 & 4.6 & 4.7 & 4.6 & 5.2 \\
\hline \multicolumn{7}{|c|}{$\begin{array}{l}\text { *: in some cases, } 12 \text { volts was not enough to operate the valve, so then } \\
\text { minimum voltage of operation was considered }\end{array}$} \\
\hline \multicolumn{7}{|c|}{$\frac{\text { Table 4: Minimum required voltage for operation at different pressure }}{\text { Minimum operating voltage (volts) }}$} \\
\hline \multicolumn{2}{|c|}{ Pressure (psi) } & \multicolumn{3}{|c|}{ Original } & \multicolumn{2}{|c|}{ Proposed } \\
\hline \multirow{2}{*}{\multicolumn{2}{|c|}{$\begin{array}{l}10 \\
20\end{array}$}} & \multicolumn{3}{|c|}{7.30} & \multicolumn{2}{|c|}{10.50} \\
\hline & & \multicolumn{3}{|c|}{8.00} & \multicolumn{2}{|c|}{12.00} \\
\hline \multicolumn{2}{|l|}{$\begin{array}{l}20 \\
30\end{array}$} & \multicolumn{3}{|c|}{9.40} & \multicolumn{2}{|c|}{13.50} \\
\hline \multicolumn{2}{|l|}{40} & \multicolumn{3}{|c|}{10.40} & \multicolumn{2}{|c|}{16.25} \\
\hline \multicolumn{2}{|l|}{50} & \multicolumn{3}{|c|}{11.00} & \multicolumn{2}{|c|}{18.50} \\
\hline \multicolumn{2}{|l|}{60} & \multicolumn{3}{|c|}{12.00} & \multicolumn{2}{|c|}{21.50} \\
\hline \multicolumn{2}{|l|}{70} & \multirow{2}{*}{\multicolumn{3}{|c|}{$\begin{array}{l}12.75 \\
13.50\end{array}$}} & \multirow{2}{*}{\multicolumn{2}{|c|}{$\begin{array}{l}24.50 \\
27.50\end{array}$}} \\
\hline \multicolumn{2}{|l|}{80} & & & & & \\
\hline
\end{tabular}

Table 5: Comparison of pressure opening time average for different nozzles

\begin{tabular}{|c|c|c|c|c|}
\hline \multirow[b]{3}{*}{ Pressure (psi) } & \multicolumn{4}{|c|}{ Average pressure opening time ( $\mathrm{m} \mathrm{sec}$ ) } \\
\hline & \multicolumn{2}{|c|}{ Quick Tee Jet } & \multicolumn{2}{|c|}{ stream jet } \\
\hline & Original & Proposed & Original & Proposed \\
\hline 30 & 4.6 & 2.1 & 4.4 & 2.8 \\
\hline 40 & 3.7 & 1.8 & 3.8 & 2.5 \\
\hline 50 & 3.4 & 1.6 & 3.9 & 2.4 \\
\hline Average & 3.9 & 1.8 & 4.0 & 2.5 \\
\hline
\end{tabular}

Plunger closing time: It was expected that this time would remarkably decrease once the plunger's weight is reduced. Besides that, the plunger closing time was expected to remain same when spraying with different nozzles rather the pressure closing time was expected to change. Table 6 presented the results for all six nozzles with different pressures.

Pressure closing time: The plunger seals the outlet orifice to stop the fluid while the cavity between the valve seat and nozzle contains some of the fluid. Thus it 
takes some time for nozzle to discharge the fluid from the valve. Therefore, pressure closing time is inversely proportional to the flow rate of the nozzle. As in the proposed design, the volume of the cavity after the outlet in orifice is reduced from $2.8-0.61 \mathrm{~cm}^{3}$ i.e., $78 \%$, thus it is expected that pressure closing time will be reduced in proposed design. However, the pressure closing time is independent of the voltage. Table 7 presents the experimental results.

Spring constant: As mentioned earlier that performance of plunger also depends on the selection of spring. The experiments suggested that the valve should not be operated at less than 24 volts because of its poor performance at lower voltages. On the other hand, the best result was found at 36 volts but solenoid valves have some limitations in terms of wire resistance. The other alternative was to find "better" spring that can reduce the plunger opening and closing time. Thus, five different springs were tested at 24 volts and 40 psi using the proposed valve with 0003 Quick Tee Jet nozzle and the results are presented in Table 8.

Table 6: Plunger closing time average at different pressure for different nozzles

Average plunger closing

time ( $\mathrm{m} \mathrm{sec}$ ) w.r.t. different pressures

\begin{tabular}{lllllll}
\multicolumn{1}{c}{$30 \mathrm{psi}$} & & $40 \mathrm{psi}$ & \multicolumn{3}{c}{$50 \mathrm{psi}$} & \\
$\begin{array}{l}\text { Nozzle } \\
\text { type }\end{array}$ & Original & Proposed & Original & Proposed & Original & Proposed \\
\hline $00015 \dagger 14.2$ & 3.2 & 14.2 & 3.3 & 13.0 & 3.4 \\
$0003 \dagger$ & 14.5 & 3.5 & 14.5 & 3.5 & 14.9 & 3.4 \\
$0006 \dagger$ & 13.4 & 3.1 & 13.5 & 3.1 & 12.9 & 2.9 \\
$0163 \ddagger$ & 14.3 & 3.0 & 14.3 & 2.8 & 13.9 & 2.9 \\
$036 \ddagger$ & 11.4 & 2.8 & 12.6 & 2.4 & 12.7 & 2.4 \\
$0667 \ddagger$ & 13.5 & 2.2 & 13.0 & 1.9 & 12.1 & 1.9 \\
\hline
\end{tabular}

$\dagger$ Quick teejet nozzle $\ddagger$ stream Jet nozzle

Table 7: Comparison of pressure closing time for different nozzles

\begin{tabular}{llrr}
\hline & & Flow rate Average pressure closing time $(\mathrm{m} \mathrm{sec})$ \\
Nozzle & $\left(\right.$ liters $\left.\mathrm{min}^{-1}\right)$ & Original & Proposed \\
\hline $00015 \dagger$ & 0.568 & 52.4 & 14.1 \\
$0003 \dagger$ & 1.140 & 14.1 & 6.2 \\
$0006 \dagger$ & 2.270 & 4.4 & 2.8 \\
$0163 \ddagger$ & 0.617 & 16.7 & 7.5 \\
$036 \ddagger$ & 1.360 & 6.6 & 3.9 \\
$0667 \ddagger$ & 2.520 & 2.2 & 2.0 \\
\hline
\end{tabular}

$\dagger$ Quick teejet nozzle $\doteqdot$ stream Jet nozzle

Table 8: Plunger opening and closing time for different springs

\begin{tabular}{llll}
\hline Spring & $\begin{array}{l}\text { Spring } \\
\text { Constant }\end{array}$ & $\begin{array}{l}\text { Plunger }(\mathrm{m} \mathrm{sec}) \\
\text { opening time }\end{array}$ & $\begin{array}{l}\text { Plunger closing } \\
\text { time }(\mathrm{m} \mathrm{sec})\end{array}$ \\
\hline NN-47 & 240 & 4.3 & 3.4 \\
Original $\dagger$ & 362 & 8.2 & 3.4 \\
M-84 & 512 & 8.2 & 2.7 \\
K-64 & 565 & 8.4 & 3.3 \\
O-49 & 1428 & 8.5 & 3.0 \\
\hline
\end{tabular}

$\dagger$ Original spring is the spring that comes with the texas remcor valve

\section{DISCUSSION}

The performance of the original and propsed solenoid valves is compared under varying conditions. This section illustrates the improvisions of the proposed solenoid valve for each phase of response time.

Plunger opening time: It is observed from Table 2 that the solenoid valve's performance improves as the applied voltage increases. Furthermore, plunger opening time significantly decreases as the applied voltage is increased. This suggests that delay time can be reduced by operating at higher level of voltage in VRA. This statement is bolstered by results in Table 3 which presents average of the plunger opening time at different level of pressures and voltages for original and proposed valves. The plunger opening time for operating voltage of 12 Volts decreases by more than $50 \%$ when its operating voltage is doubled. This decreasing factor further increased for high pressures. This trend is followed as the voltage further increases.

Due to the reduction in mass of plunger in the proposed valve, higher voltage was required to open the plunger while less voltage can keep the plunger open. At 12 volts of operating voltage, plunger takes $16.2 \mathrm{~m} \mathrm{sec}$ to open which is a long delay. As the minimum target area in VRA is 12 (width) X 12 (length) inches while average operational speed is $15 \mathrm{mph}\left(0.264 \mathrm{in} \mathrm{m} \mathrm{sec}^{-1}\right)$. Thus a time delay of $16.2 \mathrm{~m} \mathrm{sec}$. will result in skipping the length of 4.2 inches without spraying, which makes $35 \%$ of the target. This result can further deteriorate when other time delays are added.

The modifications made in proposed valve were expected to make plunger opening time longer while closing time shorter. But the experiments proved that plunger opening time is not increased significantly and the difference between the two time responses further decreases as the voltage is increased. At 36 volts, the performance of both valves is approximately same. Thus, it is recommended that proposed valve is operated at voltage of 24 volts or higher.

Pressure opening time: It can be observed from Table 4 that in both the valves, the minimum operating voltage increases as the pressure increases. However, comparing the two valves, it is found that original valve starts working at lower voltage level as compared to the proposed valve and the difference between two increases with increase in pressure.

It was expected that pressure opening time would be reduced in proposed model because the volume of proposed valve is reduced by $78 \%$. This is proved by experimental results mentioned in Table 5. It is 
noticed that proposed valve takes less time as compared to the orginal valve for both types of nozzles while working at different votages and pressures. The pressure opening time is also found to be independent of voltage and pressure variation but dependent on the nozzle type. The comparison presents that proposed vlave performs better than original one by the factor of 53\% and 37\% for Quick Tee Jet and Stream Jet nozzles respectively.

Plunger closing time: Similar to plunger opening time, this time phase also plays a critical role. During plunger closing time, the valve operates at full capacity while it is needed to be completely closed. The average plunger closing time for the original valve (plunger) was found to be $13.5 \mathrm{~m} \mathrm{sec}$. with a standard deviation of $1.3 \mathrm{~m} \mathrm{sec}$.

With the average operational speed of $15 \mathrm{mph}$ having target area of 12 (width) $\times 12$ (length) inches, this time delay causes $30 \%$ area to be sprayed extra. It can be observed from Table 6 that this error can be significantly reduced by the use of proposed plunger. For all types of nozzles at different pressures and voltages, the proposed valve outperformed the original valve and the average improvement of $10.6 \mathrm{msec}$ i.e. $79 \%$ is observed. It is also found that plunger closing time is independent of the pressure, voltage or nozzle type.

Pressure closing time: This time phase is mainly dependant on the flow rate of the nozzle. From Table 7, it is observed that the performance of proposed design is better than the original one for all types of nozzles. It also indicates that pressure closing time is inversely proportional to the flow rate of nozzle. However, the ratio of improvement in proposed valve is not same for all types of nozzles. This improvement is higher at lower flow rates as compared to higher flow rates. In comparison of the two types of nozzles, Stream Jet Nozzle provides more improvement as compared to Quick Tee Jet Nozzle. This might be due to the reason that Stream Jet Nozzle has three orifices as compared to Quick Tee Jet Nozzle which has one orifice. The improvement of performance for proposed valve is found to be in the range of $55 \%$ to $73 \%$. Among all the phases of time response delay, this phase has shown the highest improvement. The best result among all types of nozzle is achieved by Quick Tee Jet Nozzle (00015) where the time delay is reduced from 52.4 to $14.1 \mathrm{~ms}$.

Spring constant: It is observed from Table 8 that a spring with the lower spring constant will be preferred because it will reduce the plunger opening time. However, the differences among the plunger closing times for different springs having different spring constants $\mathrm{K}$ is very small and may be ignored.

Overall performance: Four sources of time delays are discussed and it is observed that proposed design of plunger performs better than the original plunger at all pressures but requires higher voltage to operate. Time delays have been decreased in all phases of time response which simultaneously assures more perfection in performance and less wastage of fluid or misapplicaiton. The average overall improvement for proposed valve is found to be $22 \mathrm{msec}$ i.e. $50 \%$ and recommended operating voltage is 24 volts or higher.

\section{CONCLUSION}

This research presented experimental analysis of the dynamic response of a 2602 Texas Remcor solenoid valve. From the previous studies, it was found that current, pressure, flow rate, spring force and plunger's mass had effect on the valve's performance. After analysis of existing design of solenoid valve, some modifications were applied to propose a new design. The original and proposed solenoid valves were operated at different pressures and different operating voltages. The proposed valve design was modified to reduce the mass of plunger and the volume of the cavity after the outlet orifice. Plunger's response time comprised of plunger opening and closing time, and pressure opening and closing time delays. Because of the reduction in mass, plunger closing time was reduced significantly while opening time remained approximately same. However, higher voltage was required to open the plunger at higher pressures while plunger closing time was found to be independent of voltage, pressure or flow rate. The reduction in volume of cavity after the outlet orifice helped to reduce the pressure opening and closing time delays. The pressure closing time was also found to be dependent on the flow rate of nozzle. The improvement of 53-37\% were observed for pressure closing time for Quick Tee Jet and Stream Jet nozzles respectively while improvement in pressure closing time was observed to be in the range of $55-73 \%$ depending on the nozzle type. The plunger closing time was improved by $79 \%$ while $34 \%$ improvement was obtained by the change of spring. The average improvement in overall performance of proposed solenoid valve is $22 \mathrm{~m} \mathrm{sec}$ or $56 \%$.

\section{ACKNOWLEDGMENT}

This project was supported by King Saud University, Deanship of Scientific Research, College of 
Food and Agriculture Sciences Reseach Center. We are thankful to Department of Biosystems and Agriculture Engineering in Oklahoma State University to provide us the platform to conduct this research.

\section{REFERENCES}

Bowers, C.G., G.T. Roberson, D.K. Cassel and G.C. Naderman, C. Brownie, 2001. Variable rate liquid nitrogen application for cotton and corn production. Proceedings of the ASAE Annual Meeting (ASAEAM'01), Paper No. 011201. http://asae.frymulti.com/abstract.asp?aid=5523\&t= 2

El-Marazky, M.S.A., F.S. Mohammad and H.M. AlGhobari, 2011. Evaluation of soil moisture sensors under intelligent irrigation systems for economical crops in arid regions. Am. J. Agri. Biol. Sci., 6: 287-300. DOI: 10.3844/ajabssp.2011.287.300

Ezrin, M.H., M.S.M. Amin, A.R. Anuar and W. Aimrun, 2010. Relationship between rice yield and apparent electrical conductivity of paddy soils. Am. J. Applied Sci., 7: 63-70. DOI: 10.3844/ajassp.2010.63.70

Holtz, A.J. R.A. Willoughby, M.L. Stone, J.B. Solie and W.R. Raun, 2000. Dynamic response of valves for variable rate application of fertilizer and pesticides. Proceedings of the ASAE Annual International Meeting, Jul. 9-12, Milwaukee, Wisconsin, USA, pp: 1-16. http://www.cabdirect.org/abstracts/20003016251.ht $\mathrm{ml}$
Liaghat, S. and S.K. Balasundram, 2010. A review: The role of remote sensing in precision agriculture. Am. J. Agric. Biol. Sci., 5: 50-55. DOI: 10.3844 /ajabssp.2010.50.55

Lu, F.K. and D.S. Jensen, 2003. Potential viability of a fast-acting micro_solenoid valve for pulsed detonation fuel injection. Proceedings of the 41st AAIA Aerospace Science Meeting (AAIAASM'03), Paper No. AIAA 2003-0888. http://arc.uta.edu/publications/cp_files/AIAA\%202 003-0888.pdf

Pohl, J., M. Sethson, P. Krus and J.O. Palmberg, 2002. Modeling and simulation of a fast switching valve intended for combustion engine valve trains. Proc. Instit. Mech. Eng., Part I: J. Syst. Control Eng., 216: 105-116. DOI: 10.1243/0959651021541462

Shengchang, Z., X. Yangzeng, S. Guanglin and Z. Tingxiu, 2001. Study on extra-high speed digital valve. Proceedings of the 5th International Conference On Fluid Power Transmission And Control, Apr. 3-5, Hangzhou, China, pp: 165-168. http://www.csa.com/partners/viewrecord.php?requ ester $=$ gs \&collection $=$ TRD\&recid $=200206611985$ MT

Zheng, Q., 2001. Characterization of the dynamic response of a cylinder deactivation valvetrain system. SAE Technical Paper 2001-01-0669. DOI: 10.4271/2001-01-0669 